\title{
EL SALÓN FUERA DEL SALÓN: CORPOREIDAD EN LOS ANTIGUOS SALONES DE BAILE DE LA CIUDAD DE MÉXICO Y SU DESPLAZAMIENTO HACIA LA PLAZA PÚBLICA
}

\author{
THE BALLROOM OUTSIDE THE BALLROOM: EMBODIMENT IN THE OLD-TIME \\ BALLROOMS OF MEXICO CITY AND ITS SHIFTING TO THE PUBLIC SQUARE
}

O SALÃO DE BAILE FORA DO SALÃO DE BAILE: CORPORALIDADE NAS ANTIGAS SALAS DE DANÇA DA CIDADE DO MÉXICO E SEU MOVIMENTO EM DIREÇÃO À PRAÇA PÚBLICA

Carla Verónica Carpio Pacheco ${ }^{1}$

Resumen

\begin{abstract}
En la década de los años treinta del siglo xx la ciudad de México fue testigo de un amplio proceso de urbanización que trajo consigo nuevas formas de habitar la ciudad. Con la concentración de personas en diversos núcleos urbanos se configuraron nuevas dinámicas de movilidad ligadas a los ritmos de trabajo. Asimismo, emergieron formas de disfrute y socialización entre varios sectores de la población que antes restringía el tiempo de la fiesta a los calendarios agrícolas o religiosos. Este artículo de reflexión da cuenta de los antiguos salones de baile como espacios de aprendizaje corporal que inscribieron un habitus particular en los asistentes, lo cual configuró una comunidad de baile que perdura hasta nuestros días, aun cuando la mayoría de esos recintos hayan cerrado sus puertas. En efecto, desde finales del siglo pasado, la comunidad de baile reproduce y actualiza su práctica en plazas públicas que resignifican el espacio urbano y las lógicas propias del salón de baile.
\end{abstract}

Palabras clave: danza popular; urbanización; expresión corporal; socialización

\section{Abstract}

\begin{abstract}
In the decade of the 1930s, Mexico City witnessed a broad urbanization process entailing new ways of dwelling in the city. With the concentration of people in different points of the city, new mobility dynamics arose, linked to working rhythms. Likewise, enjoyment and socialization ways came up among various population groups, which formerly restricted their feasting time to agricultural or religious calendars. This reflection article provides an account of the old-time ballrooms as spaces for body learning, that stamped a singular habitus on their frequenters, which configured a dance community that lasts until this day, even though most of those places have already closed their doors down. In fact, since the end of the last century, the dance community has replicated and updated its past performance in public squares, thus resignifying the urban space and the very logic of a ballroom.
\end{abstract}

Keywords: folk dance; urbanization; physical expression; socialization

1 Doctoranda en el Programa de Estudios Latinoamericanos de la UnAm. Maestra en Estudios políticos y sociales. Licenciada en Sociología.carpa.cv@gmail.com. Orcid: 0000-0002-0779-2376. 
Nos anos trinta do século xx, a Cidade do México testemunhou um amplo processo de urbanização que trouxe novas maneiras de habitar a cidade. Com a concentração de pessoas em vários centros urbanos, novas dinâmicas de mobilidade foram ligadas a ritmos de trabalho. Da mesma forma, surgiram formas de diversão e socialização entre os vários setores da população que anteriormente restringiam o horário das festas a calendários agrícolas ou religiosos. Este artigo de reflexão da conta dos antigos salões de dança como espaços para a aprendizagem do corpo que inscreviam um habitus particular nos participantes, o que configurou uma comunidade de dança que dura até os dias de hoje, mesmo que a maioria desses locais tenha fechado suas portas. De fato, desde o final do século passado, a comunidade de dança reproduz e atualiza sua prática em praças públicas que redefinem o espaço urbano e a lógica do salão de dança.

Palavras-chave: dança popular; expressão corporal; socialização

Fecha de recepción: 18 de enero de 2019

Fecha de evaluación: 02 de febrero de 2019

Para citar este artículo:

Carpio Pacheco, C. V. (2019). El salón fuera del salón: corporeidad en los antiguos salones de baile de la ciudad de México y su desplazamiento hacia la plaza pública. Lúdica Pedagógica, 29, 47-55. https://doi. org/10.17227/ludica.num29-11085 


\section{INTRODUCCIÓN}

Los salones de baile surgieron en el contexto del proceso de urbanización de Ciudad de México. Como parte de ese proceso se modificaron horarios y rutinas de trabajo pero también formas de re-creación, pues como señala la antropóloga Amparo Sevilla (2005)

La ciudad es un espacio construido, el cuerpo es el espacio biológico de la acción. Es por ello que todo proceso de urbanización ha implicado una adecuación ideológica y corporal a dicha construcción social, a través de varios mecanismos de control que exigen, entre otras cosas una disciplina del cuerpo humano (p. 130).

De modo que entre los años veinte y cincuenta del siglo XX no solo proliferaron los salones de baile en la ciudad de México, sino que se configuró una educación corporal citadina. Esto significa que la entonces novedosa dinámica urbana dio lugar a espacios y tiempos específicos para el goce y la socialización, donde el cuerpo mismo de los citadinos tuvo que adaptarse y generar nuevas formas de habitar el espacio urbano, así fue como

la ciudad abrió la posibilidad de celebrar sin conmemorar, dando lugar a fiestas de carácter privado que no necesariamente atienden a fechas establecidas en ningún calendario y, sin embargo, al presentar cierta periodicidad dichas fiestas constituyen también una forma de estructurar el tiempo y el espacio colectivo e individual (Sevilla, 2005, p. 345).

La creciente migración del campo a la ciudad y la industrialización de la misma trajo, entre otras consecuencias, la conformación de un proletariado compuesto en gran medida por jóvenes en búsqueda de actividades recreativas al finalizar la jornada fabril. De modo que las festividades que antiguamente se organizaban en torno a un calendario religioso o agrícola, y que tenían lugar en calles y lugares públicos donde el baile era una actividad central, fueron poco a poco sustituidas por espacios como el salón de baile, donde se podía asistir toda la semana, en horarios que se ajustaban a las jornadas laborales de la dinámica urbana. Estos nuevos templos del buen bailar (Sevilla, 2003) eran espacios cerrados donde se cobraba la entrada, y las cuotas se adaptaban a todos los bolsillos, lo cual configuró comunidades diferen- ciadas de acuerdo a los lugares donde se ubicaba el salón, el costo de la entrada y los sectores de la población que asistían.

Por ejemplo, en 1920 abre sus puertas el legendario Salón México, que fue el primero en la capital en registrarse bajo el rubro de salón de baile. A este recinto, conocido también como El Marro, acudía un público heterogéneo compuesto por choferes, empleados, meseros, obreros, mecánicos, albañiles, amas de casa, costureras y empleadas domésticas, quienes asistían después de sus jornadas laborales a bailar al salón a partir de las seis de la tarde y por lo general se retiraban antes de la medianoche pues debían trabajar al día siguiente. Los y las bailadores(as) se distribuían en las tres salas que el público bautizó como El sebo, La manteca y La mantequilla, por la diferencia de olores y de gente que asistía a cada una de ellas. Al primero acudían las personas de más bajos recursos, que incluso asistían descalzos a bailar; el segundo era más bien para comerciantes y empleados, mientras que el tercero era el más "exclusivo", frecuentado por algunos personajes reconocidos de la política o del espectáculo, o bien por "extranjeros o intelectuales que de vez en cuando se dejaban caer por El Marro para experimentar en carne propia cómo se divertía la chusma" (Flores y Escalante, 2006, p. 109).

Después del auge de los salones de baile, para las décadas de los años sesenta y setenta, estos recintos fueron cerrando de modo paulatino debido a varias razones. Por un lado, la proliferación del rock and roll y la música disco entre las nuevas generaciones que demandaban otro tipo de espacios. Por otro lado, los antiguos salones fueron víctimas de la escrupulosa reglamentación que el regente de hierro Ernesto Uruchurtu realizó en la ciudad y que terminó con gran parte de la diversa vida recreativa nocturna que durante el régimen anterior proliferó pese a las restricciones. Por tal motivo, durante su largo mandato (1952-1966) se clausuraron algunos lugares y se impuso un nuevo horario a cantinas, cabarets y salones de baile, estos últimos desde entonces debían cerrar sus puertas a la una de la mañana y no vender bebidas alcohólicas.

Según el discurso oficial, con estas medidas se buscaba cuidar la economía del trabajador, para que este no malgastara su salario en tertulias y borracheras. 
Lo cierto es que los salarios eran muy bajos y no había aumento, de modo que como afirma el escritor Carlos Monsiváis (1996) "La ciudad festiva se congela en la sordidez de la gazmoñería, así luego de la moralización el salario obrero tampoco alcance para nada" (p. 28). De modo que a partir de 1957 comienza el cierre y quiebre masivo de salones de baile en Ciudad de México, de los cuales solo han sobrevivido dos representantes, Los Ángeles y el California Dancing $C l u b$, que conservan casi en su totalidad las características originales de los antiguos salones.

Si bien la tendencia durante la primera mitad del siglo xx había sido llevar el baile a recintos como los salones de baile construidos específicamente para ser espacios siempre festivos con horarios que atendieran a la nueva dinámica de los trabajadores de la ciudad, la tradición de realizar celebraciones en las calles no se perdió del todo, solo fue regulada en mayor medida por las autoridades o bien tomó otras formas y se desplazó a zonas periféricas de la ciudad, como por ejemplo el caso de los sonideros a partir de los años sesenta y setenta.

En la última década del siglo pasado, las políticas culturales en Ciudad de México dieron otro giro y empezaron a promover la reapropiación de plazas públicas con fines recreativos, en particular con actividades dirigidas a personas de la tercera edad. En ese contexto se incentivó el uso de la plaza de la Ciudadela para bailar danzón y otros bailes propios de los antiguos salones.

Como veremos en este artículo, existen actores sociales que son fundamentales dentro de la comunidad de baile, ya que han contribuido a través de sus prácticas y de la formación de nuevas generaciones de bailadores a que el salón salga del salón, es decir, que más allá del espacio físico de los extintos salones de baile se mantenga y actualice la tradición del baile popular en la apropiación de diversas plazas públicas.

En esta investigación se abordó el caso del salón Los Ángeles, que en la actualidad es el más antiguo de la capital mexicana y de la plaza de la Ciudadela. Veremos que el salón de baile que surgió en el contexto urbano del siglo xx constituyó un espacio pedagógico de la nueva dinámica corporal. El objetivo es mostrar de forma comparativa cómo se configuró un habitus de los bailadores en los antiguos salones que involucra una serie de códigos, gestos, movimientos y disposiciones corporales que se replican en el salón abierto, es decir, en las plazas públicas, aunque con adaptaciones y resignificaciones que han permitido que a pesar del cierre de los recintos, el espacio simbólico del salón no se extinga y, por el contrario, se siga reproduciendo.

\section{"QUIEN NO CONOCE LOS ÁNGELES NO CONOCE MÉXICO"}

El salón Los Ángeles se fundó en 1937 bajo el nombre de Centro Social Los Ángeles, en la calle Lerdo No. 206, en el popular barrio de la colonia Guerrero. Su nombre hace alusión a la iglesia de Nuestra Señora de Los Ángeles ubicada a un costado del salón. Su historia se remonta a principios del siglo $\mathrm{XX}$, cuando el señor Miguel Nieto Alcántara construyó un corralón en el terreno del actual salón para almacenar carbón y madera. Sin embargo, a mediados de la década de los treinta, el carbón y la leña dejaron de utilizarse como combustibles domésticos cotidianos y el negocio se volvió poco rentable. Por otro lado, los salones de baile habían comprobado ser una empresa muy fructífera, así que el señor Nieto decide cambiar de giro comercial y aprovechar el material de la Maderería Monte Alto, propiedad de la familia, para decorar y amueblar el lugar, además de elaborar una gran pista de 1500 metros cuadrados (Sevilla, 2001, p. 40).

El señor Miguel Nieto Hernández, hijo del dueño original y responsable del lema del lugar, continuó la tradición junto con su esposa Armida Applebaum, que a su vez ha mantenido hasta la fecha el negocio familiar con sus hijos Miguel y Enrique Nieto, aun después de la muerte de su marido. La señora Applebaum nos comenta que la asistencia ha disminuido, pues el salón tiene capacidad para 4 mil personas, y ella calcula que antes ingresaban hasta 2 mil personas en un día normal, mientras que en la actualidad solo asisten entre 500 y 600 personas de forma regular, a menos que haya algún evento especial donde pueden entrar hasta 3 mil personas. Un número bastante elevado si se piensa en cualquier otro recinto contemporáneo dedicado al baile, pero insuficiente 
si se calcula el gasto que implica mantener un lugar tan grande con tres orquestas al día, trabajadores y servicios de luz eléctrica y agua potable.

La fachada del salón Los Ángeles se asemeja a los antiguos cines que existieron en Ciudad de México, con una amplia marquesina y una taquilla a la entrada, solo que en este caso se aprecia el escudo del salón con la histórica leyenda "Quien no conoce los Ángeles no conoce México”.

Todos los asistentes se arreglan de forma especial para ir a bailar: las mujeres con falda o vestido y zapatos altos; los varones con camisa, zapatos de charol, ante o piel de colores combinados, y uno que otro con sombrero. Algunas mujeres agitan sus abanicos y los hombres sacan sus pañuelos, ambos elementos necesarios cuando el cuerpo no para de moverse y el sudor puede resultar desagradable para la pareja o hasta peligroso si llega a caer al piso. La tradición de usar abanico viene de los lugares costeños donde se origina el danzón, como Veracruz, Yucatán y la isla de Cuba, que son muy calurosos. Otro elemento importante dentro del aseo personal es el aliento, por la cercanía con la pareja de baile, así que las pastillas, chicles y enjuague bucal son indispensables en el tocador del salón, así como la disposición de algunos perfumes o lociones para disimular el aroma después de algunas piezas de baile.

El público que asiste de modo regular oscila entre los cincuenta y ochenta años de edad, y en su mayoría llegan en parejas, algunas mujeres lo hacen en pequeños grupos, los hombres asisten en pareja o solos, de cualquier forma, encontrarán a viejos conocidos y conocidas en el interior.

Algunos bailadores, sobre todo aquellos que no llevan pareja, caminan a lo largo de la pista, en busca de caras conocidas para invitar a bailar o para saludar, otros permanecen en un extremo de la pista observando. Y es que al salón se asiste a bailar, pero también $a$ ver bailar, el salón es un escenario donde se aprenden comportamientos, gestos, vestuarios, etc., que configuran un habitus de los bailadores.

Recordemos que para el sociólogo Pierre Bourdieu (1997), el habitus constituye una serie de "principios generadores de prácticas distintas y distintivas [...] principios de clasificación, principios de visión y divi- sión" (p. 20) que generan disposiciones en los agentes. El cuerpo es fundamental en la configuración y reproducción de un habitus compartido en el salón de baile, que está atravesado por las tensiones en la distribución del capital cultural y que repercuten en la ubicación de los actores dentro del campo social. En este caso, la tradición legitima a los miembros de la comunidad y la destreza en el baile junto con un comportamiento adecuado, ponen en evidencia el capital simbólico y cultural de los asistentes.

Por lo tanto, cuando utilizamos el término observar en el ámbito del baile se hace referencia a una disposición corporal que va más allá de la mirada y que rebasa los pasos de baile, pues en el aprendizaje corporal sin necesidad de que la palabra intervenga, los bailadores imitan gestos, miradas, caminados y desplazamientos en la pista, además de los movimientos propios del baile. Esto es lo que el antropólogo Thomas Csordas (2011) denominó modos somáticos de atención, para hacer referencia a las formas culturalmente determinadas de poner atención con el cuerpo, lo cual implica asumir una condición existencial particular de acuerdo con el contexto donde se encuentran los participantes. Como veremos, estas formas de poner atención desde el propio cuerpo a la presencia corporizada de los demás participantes atraviesan el desarrollo de la práctica y permiten el aprendizaje de formas de ser que ubican a los actores sociales dentro y fuera de la pista.

Por ejemplo, en una de mis visitas al salón pude identificar a uno de los observadores, de nombre David, un bailador que también asiste a la plaza de la Ciudadela, donde es intructor de clases de danzón. Según me comentó, cuando asiste al salón le gusta bailar, pero también se muestra dispuesto para aprender el comportamiento de salón y de esa manera llevarlo a su práctica dentro de sus propias clases. En el proceso de investigación pude registrar que su comportamiento es diferente al que tiene en la Ciudadela, pues en el salón es discreto y aunque baila algunas piezas, la mayor parte del tiempo permanece observando, quizá porque es consciente de que el público del salón es más especializado y se puede encontrar con figuras reconocidas dentro de la escena del baile.

Uno de esos personajes es Jesús Uvalle, oriundo del barrio de Tepito, aunque nacido en Guanajuato, es 
muy ampliamente conocido como "El Gato" dentro de la comunidad de baile. Jesús también es maestro en la plaza de la Ciudadela y, según nos comenta, en sus clases implementa una "metodología de enseñanza" que ha perfeccionado a lo largo de los años y aunque nunca tomó clases de baile ni es bailarín de academia se considera diferente de "los líricos". Entiende que muchas personas necesitan ganarse un poco de dinero, pero no le parece justo que no enseñen "correctamente" el danzón y hagan mezclas con pasos de otros bailes. En cambio, su metodología "no solo educa los pies y los oídos de los bailadores", sino que enseña todos los secretos de los pachucos, como portar de forma adecuada el traje, adoptar cierta manera de andar y hasta prepararse para dar entrevistas.

Por ello, nos comenta que propondrá en la alcaldía que solo se permita impartir clase a los maestros que "realmente" están preparados, y no a personas que no saben bailar pero que la gente les otorga el título de "maestros", pues "hay que pensar en la preparación de futuras generaciones". También está en desacuerdo con que haya pachucos que no sepan portar el traje y que se confunda la figura del pachuco con la del "padrote". Lucha porque se conserve la tradición, pero de manera "informada", es decir, con los elementos propios del pachuco clásico y con su elegancia característica.

Este es un punto importante, pues de acuerdo con las observaciones en el trabajo de campo, ser pachuco es más bien una actitud, una forma de ser, y en última instancia, un habitus que atraviesa todos los sentidos y posiciona a quienes lo incorporan en el espacio social. El pachuco utiliza el zootsuit característico que los jóvenes chicanos vestían a principios del siglo pasado y que el actor Germán Valdés Tin-Tan popularizó a través de sus películas. Este traje consiste en un saco de espalda ancha, holgado, pantalones bombachos y entubados en los tobillos, sombrero con pluma, cadena, flor en el ojal y zapatos de colores combinados. La actual excentricidad del ya de por sí exagerado traje de pachuco es también una manera de distinguirse y sobresalir dentro de las modas actuales, saturadas de elementos y estímulos visuales, por ello los colores y algunos otros detalles se han exagerado como una manera de sobrevivir sin perder el carácter trasgresor que tenían desde su origen.
Por ejemplo, el día de la entrevista que realicé con "El Gato" mencionó que le gusta innovar en los colores pues antes las telas de los trajes eran muy "serias", así que ahora prefiere buscar en las telas "de mujer" antes que usar colores parcos. En aquella ocasión portaba un traje rosa claro, al igual que la camisa, la corbata y el sombrero con larga pluma, combinado con los zapatos blancos confeccionados por "Shivata". ${ }^{2}$ El calzado es un elemento fundamental, pues resalta el ágil desplazamiento de los pies o disimula la torpeza de los bailadores novatos. Por ello, los zapatos deben ser especiales para el día de baile, aunque si la situación económica no permite adquirir zapatos especiales, los que se usen tienen que brillar más ese día, por lo cual siempre se encuentran "boleros"3 en la cercanía de plazas y salones. Para las mujeres el tacón alto o mediano es casi obligatorio, ya sea en color negro, o bien en los colores que combinan con el vestido, casi siempre vistoso y brillante. En el caso de los hombres hay un sin fin de modelos, casi todos ellos puntiagudos, con un tacón mediano y de texturas y colores muy diversos, piel de cocodrilo, charol, gamuza, blancos, negros, rojos, amarillos, verdes, etc.

\section{LA PLAZA DEL DANZÓN}

Una de las plazas públicas donde se baila hoy en día es conocida como La Ciudadela que se ubica en la colonia centro de la Ciudad, a un costado del histórico edificio que alberga la Biblioteca de México José Vasconcelos y del cual toma su nombre. ${ }^{4}$ En este lugar se instaló la Plaza del danzón desde 1996, y cada sábado se reúnen ahí personas de todas las edades, aunque la mayoría rebasan los sesenta años.

La alcaldía de Cuauhtémoc proporciona los elementos necesarios para que cada fin de semana acudan decenas y a veces cientos de personas para disfrutar del danzón. Como testimonio de ello existe una

2 Apodo con que se conoce al vendedor de zapatos especializados para baile que tiene su taller en el famoso barrio de La Lagunilla, y que asiste al salón Los Ángeles y la plaza de la Ciudadela para ofrecer sus productos.

3 Así se conoce al oficio de las personas que pintan o abrillantan los zapatos y que se ubican en calles o plazas.

4 Este edificio fue sede de la Real fábrica de tabacos de la Nueva España, cuartel militar y última prisión del insurgente José María Morelos y Pavón, motivo por el cual la plaza también recibe su nombre. 
placa que se ubica debajo del escenario y que develó la entonces jefa delegacional en el año 2002 para conmemorar el séptimo aniversario de lo que se denominó Plaza del danzón.

El apoyo gubernamental también se manifiesta en elementos poco tangibles a simple vista pero fundamentales para el funcionamiento de la plaza, como la asignación de policías, los permisos correspondientes para ofrecer clases de baile y música viva, para colocar puestos comerciales y estacionar autos. Sin embargo, aquellos que dan vida a la Plaza del danzón son las personas que asisten cada sábado y que han adoptado este espacio como algo más que un lugar de baile, como un centro de reunión que les resulta familiar y propio.

Según nos comenta una pareja entrevistada, se alterna cada sábado entre música grabada y danzoneras en vivo, además se ha cambiado la distribución de la plaza, pues antes el escenario se encontraba del lado opuesto al que se encuentra ahora, y en el centro de la plaza los restos de una fuente servían para delimitar la pista de baile. El escenario está techado y cuenta con un potente equipo de sonido y una maestra de ceremonias que conoce a varios de los asistentes a quienes envía saludos por el micrófono.

La peculiaridad de la plaza de la Ciudadela es que está atravesada por una pequeña calle que la divide en una parte más pequeña, la Plaza del danzón, de otra más grande y cercana al edificio de la Biblioteca de México conformada por una gran explanada-jardín donde también se ha expandido la práctica de baile, aunque sin la infraestructura de la primera. En esta se localizan diversos instructores de baile que no cuentan con mayores recursos que una grabadora y en algunos casos un amplificador. La variedad de ritmos que enseñan van desde danzón, salsa, merengue y cumbia, hasta rock n'roll y swing, por lo cual el público en general es más joven que los asiduos a la Plaza del danzón.

Este lugar es importante pues constituye una especie de antesala simbólica de la Plaza del danzón, ahí algunas parejas menos experimentadas practican rutinas y figuras, o bien tratan de aprender algo en las clases, antes de adentrarse de lleno en el danzón.

En el otro extremo de la plaza donde se imparten clases se localiza un grupo de música afroantillana, conocida coloquialmente como "tropical" cuyo repertorio se compone sobre todo de salsa, son y cumbia. Este grupo no ofrece clases, solo toca para que la gente baile a cambio de cooperación voluntaria, lo cual diversifica y amplía el campo del baile y atrae a más público. Su ubicación, más cercana al metro y a la avenida principal, así como el tipo de música que ejecutan, facilitan el acceso y la integración de un público más heterogéneo, donde alternan algunos bailadores tradicionales de la Plaza del danzón, con bailadores jóvenes y hasta público ocasional que a veces se conforma con escuchar la música y observar.

La ubicación de los tres espacios que mencionamos conforman el espacio social del baile a través del cual se ejerce una especie de filtro simbólico, invisible para los que están inmersos en él, pero que configura una tradición urbana de baile popular, con agentes más o menos expertos que participan de un proceso de pedagogía corporal.

Por último cabe señalar que el danzón, como la mayoría de los bailes de salón, se llevan a cabo en parejas compuestas por una mujer y un varón, incluso en el excepcional caso de que esté compuesta por dos hombres o dos mujeres, uno de los integrantes realiza la función masculina y otro la femenina. En efecto, el papel de cada uno está definido con claridad: el hombre dirige, la mujer lo sigue, un hombre diestro es aquel que sabe guiar a través de diversos pasos, vueltas y rutinas, mientras que una mujer hábil debe saber responder en cada caso y "dejarse llevar".

En la literatura sobre danza se ha debatido este rol "pasivo" de las mujeres, argumentando que el ser receptivas a las señales y movimientos del compañero también forma parte del desarrollo de una capacidad cinética importante a partir del cual funciona la pareja de baile. Sin embargo, no puede perderse de vista lo que señala la antropóloga María Julia Carozzi (2011), que la existencia de "secretos" reservados a varones en el baile revela una estructura que se reproduce y afirma una relación de poder entre los géneros.

En su investigación sobre el tango y las milongas porteñas ha recopilado testimonios de bailarinas que afirman que el rol de la mujer está ligado con la ignorancia de ciertos aspectos del baile, y en ese sentido, la ignorancia o el desconocimiento contituyen 
una "virtud" para ellas. A partir de esto, menciona la utilización de expresiones como "mujer liviana" para referirse a mujeres que se dejan llevar y no ponen resistencia, frente a "mujeres pesadas" que denotan un aspecto negativo en el desarrollo de la pareja. De modo que

realizar movimientos autogenerados, ya sea intencionalmente o no, que obstaculicen el desarrollo de los improvisados por el varón es para los milongueros más antiguos (...) un pecado mortal femenino. Se dice de las mujeres que "se mueven" sin que el varón se lo indique, que "bailan solas", "que se adelantan", que "se anticipan", que "acarrean a los varones", o que bailan como "camioneros" (...) de todas ellas se afirma que "quitan libertad" al varón que baila con ellas" (Carozzi, 2011, p. 247).

En el caso del danzón ocurre algo similar, lo cual se ve reflejado incluso en las entrevistas que realicé, puesto que las mujeres no querían hablar porque consideraban que "no sabían tanto" o bien hablaban muy poco y preferían dar la palabra a sus parejas, quienes se extendían cuando hablaban de sus conocimientos y hazañas en el danzón. Incluso pude notar que no existe una figura femenina parecida al pachuco, aunque algunos denominan "pachucas" a las que bailan con ellos, estas no son actores definidos, ni poseen elementos consistentes para caracterizarlas, pareciera que su rol se limita a ser acompañantes.

También se pudo constatar que, contrario a lo que ocurre con los varones, las mujeres casi siempre asisten en pareja o en grupo, y aunque también observan, tanto en el salón como en la plaza la forma de invitar a bailar es unidireccional, de los hombres hacia ellas. En ocasiones basta una mirada desde lejos, una seña con las manos, y en otras es necesaria una petición directa y un agradecimiento al terminar la pieza.

Sin embargo, no hay que dejar de lado que en el momento histórico de su aparición los salones de baile constituyeron espacios donde muchas mujeres por primera vez podían asistir "solas" sin ser juzgadas, en parte también porque se incorporaban a la vida laboral fuera del hogar, lo cual significaba una relativa libertad para ellas, que favorecía la posibilidad de bailar con quien desearan, conocido o desconocido, y no solo con su pareja formal.

\section{A MODO DE CIERRE}

Concluimos que no existe un desplazamiento de las plazas respecto a los salones ni viceversa, ambos forman parte del subcampo del baile popular. En ambos lugares existen comunidades sólidamente constituidas que trascienden los espacios físicos y configuran un espacio simbólico con reglas, normas y códigos implícitos que son reconocidos e incorporados por dicha comunidad.

Lejos de existir una disputa entre los salones y las plazas, existe una relación recíproca, se implican los unos a los otros y se retroalimentan entre sí. En efecto, los nuevos espacios públicos donde se mantiene la práctica del baile reproducen, resignifican y recrean los códigos, jerarquías y rituales de los salones casi extintos, pero están muy lejos de ser copias de los antiguos salones, por el contrario, se nutren de ellos para dar forma a un espacio nuevo, más abierto, informal y diverso. Los elementos que incorporan las plazas tienen en común la flexibilidad que facilita que nuevas generaciones se acerquen a los antiguos bailes de salón.

Por último, cabe señalar que, si bien son importantes las políticas públicas que las alcaldías han implementado respecto a la recuperación de espacios públicos, no son estas la única causa de que la comunidad de baile se mantenga, sino que esta ha generado estrategias de cohesión cuyas actividades demandan lugares recreativos.

Siguiendo a Bourdieu podemos afirmar que los distintos habitus de los agentes que conviven en el espacio social configuran las reglas y son configurados por ellas, dentro del subcampo social donde se inscriben. Es decir, que los bailadores han creado un lenguaje codificado del baile en la misma medida en que son producto de este. Por ejemplo, la variedad de formas de ejecutar el danzón que surgieron en Ciudad de México: "de fantasía, clásico, abierto, cerrado, floreado, acubanado, de rutinas, de coreografía", y al mismo tiempo encontramos una forma de ser y estar que incorpora formas particulares de moverse, de mirar y de habitar el espacio de baile, sea este abierto o cerrado. 


\section{REFERENCIAS}

Aguilar, M., Sevilla, A., Vergara, A. (Coords.) (2001) La ciudad desde sus lugares. Trece ventanas etnográficas para una metrópoli. México: Miguel Ángel Porrúa.

Bourdieu, P. (1997). Razones prácticas. Barcelona: Anagrama.

Carozzi, J. (2011). Ni tan pasionales ni tan decentes: tras las huellas de la liviandad en las clases de tango milonguero y las milongas céntricas porteñas. Las palabras y los pasos. Etnografías de la danza en la ciudad (pp. 223262). Buenos Aires: Gorla,

Csordas, T. (2011). Modos somáticos de atención. En S. Citro (Coord.). Cuerpos plurales. Antropología de y desde los cuerpos (pp. 83-104). Buenos Aires: Biblos.
Flores Escalante, J. (2006). Salón México. Historia documental y gráfica del danzón en México. México: Asociación mexicana de estudios fonográficos.

García Canclini, N. (Coord.) (2005). La antropología urbana en México. México: Conaculta, UAM, FCE.

Monsiváis, C. (27 de mayo de 1996). El mito de Uruchurtu, mezcla de eficacia con paternalismo represivo. Proceso.

Sevilla, A. (2003). Los templos del buen bailar. México: Conaculta. 